\title{
Letter \\ Clinical value of an arterial pressure-based cardiac output measurement device
}

\author{
Joris Lemson and Johannes $\mathrm{G}$ van der Hoeven
}

Department of Intensive Care Medicine, Radboud University Nijmegen Medical Centre, 6500 HB Nijmegen, The Netherlands

Corresponding author: Joris Lemson, j.lemson@ic.umcn.nl

Published: 25 January 2008

Critical Care 2008, 12:403 (doi:10.1186/cc6219)

This article is online at http://ccforum.com/content/12/1/403

(c) 2008 BioMed Central Ltd

See related research by McGee et al., http://ccforum.com/content/11/6/R105

With interest we read the recent publication by William McGee and colleagues in which they conclude that arterial pressurebased cardiac output (APCO) measurement is comparable to intermittent thermodilution cardiac output (ICO) [1].

However, the Bland Altman plot of APCO versus ICO shows a wide spread of data points with a percentage error of $42 \%$. These large variations could lead to a completely different clinical management. Also, we disagree that a percentage error less than $28 \%$ is a conservative requirement. By using an error-gram, limits of precision of $\pm 20 \%$ for both test and reference method give predicted limits of agreement of $28.3 \%$ [2]. These limits should be respected when an alternative cardiac output measurement technique is evaluated because limits of precision in excess of $20 \%$ for a single technique are not clinically acceptable.
Furthermore, the authors state that they only consider a change in cardiac output of $30 \%$ or more clinically relevant. This is in contrast to daily clinical practice in which cardiac output changes of $10 \%$ to $15 \%$ are frequently used for making decisions regarding therapy. Also, they have calculated the change in cardiac output by dividing the delta cardiac output by the mean value before and after the change. In this way they have artificially decreased the relative change in cardiac output. Subsequently, in the plot showing the change in ICO versus the change in APCO, it can be observed that when changes in ICO of more than $15 \%$ are analyzed, in only $35 \%$ of the cases did the APCO also change $15 \%$ or more in the same direction. Moreover, in $45 \%$ of the cases the APCO changed in the opposite direction!

Based on the results of this study, we think that APCO is not accurate in measuring absolute values of cardiac output, nor in tracking changes in cardiac output in a general intensive care population.

\section{Authors' reply \\ William T McGee}

Few data support the use of any therapy based on hemodynamic variables to improve outcome in intensive care unit (ICU) patients. In the recently completed FACTT trial, therapy based on cardiac output had no impact on patient outcome [3]. Other trials targeting cardiac output as a treatment variable have had disappointing results [4].

In our study of ICU patients exhibiting a broad range of physiological variability, the limits of precision for ICO are $\pm 36 \%$ simply for consecutive measures of ICO. Our ICO measurements are likely to reflect greater precision than usual practice as the investigators would frequently obtain additional (more than four) measurements in an attempt to maximize reliability of the ICO data during the trial, selecting the four measures in best agreement. In two trials involving more homogeneous groups of patients precision was similar $[5,6]$.

A change in cardiac output of $15 \%$ or less should not prompt a change in management by itself. Basing treatment 
decisions on cardiac output changes of $10 \%$ to $15 \%$ likely results in unnecessary hemodynamic manipulation of unknown clinical impact and we would strongly discourage this practice in the absence of other clinically relevant information [7].

Both continuous methods (continuous cardiac output [CCO] and APCO) track dynamic change in cardiac output utilizing ICO as a reference in a remarkably similar fashion. Although the absolute magnitude of cardiac output change with either continuous measure is rarely identical to a simultaneous ICO measurement, both continuous methods track $\triangle \mathrm{ICO}$ acceptably well within $\pm 30 \%$ (96\% of the time for APCO and $95 \%$ of the time for CCO using this well accepted technology). Breukers and colleagues [5] found concordance of delta cardiac output in $75 \%$ of determinations comparing ICO to APCO.

APCO is a promising minimally invasive technology that offers great safety advantages over standard techniques utilizing a pulmonary artery catheter when determination of cardiac output is thought to be important for patient care in the ICU.

\section{Competing interests}

Edwards Lifesciences, Irvine, CA provided a research grant for the execution of the study. WTM has received consulting fees from Edwards Life Sciences and is also on a speakers' panel for Edwards Lifesciences. Edwards Lifesciences holds or has applied for all patents related to the FloTrac/Vigilio System.

\section{References}

1. McGee WT, Horswell JL, Calderon J, Janvier G, Van ST, Van den BG, Kozikowski L: Validation of a continuous, arterial pressurebased cardiac output measurement: a multicenter, prospective clinical trial. Crit Care 2007, 11:R105.

2. Critchley LA, Critchley JA: A meta-analysis of studies using bias and precision statistics to compare cardiac output measurement techniques. J Clin Monit Comput 1999, 15:85-91.

3. The National Heart, Lung and blood Institute Acute Respiratory Distress Syndrome (ARDS) Clinical Trials Network: Pulmonaryartery versus central venous catheter to guide treatment of acute lung injury. $N$ Engl J Med 2006, 354:2213-2224.

4. Shah MR, Hasselblad V, Stevenson LW, Binanay C, O'Connor CM, Sopko G, Califf RM: Impact of the pulmonary artery catheter in critically ill patients: meta-analysis of randomized clinical trials. JAMA 2005, 294:1664-1670.

5. Breukers R-M, Sepehrkhouv S, Spiegelenberg SR, Groeneveld $A B J$ : Cardiac output measured by a new arterial pressure waveform analysis method without calibration compared with thermodilution after cardiac surgery. J Cardiothor Vasc Anes 2007, 21:632-635.

6. Manecke G, Auger WR: Cardiac output determination from the arterial pressure wave: Clinical testing of a novel algorithm that does not require calibration. J Cardiothor Vasc Anes 2007, 21:3-7.

7. Connors AF Jr, Speroff T, Dawson NV, Connors AF Jr, Speroff T, Dawson NV, Thomas C, Harrell FE Jr, Wagner D, Desbiens N, Goldman L, Wu AW, Califf RM, et al.: The effectiveness of right heart catheterization in the initial care of critically ill patients. JAMA 1996, 276:889-897. 